\title{
Gestão de pessoas em uma unidade pediátrica na perspectiva do diagnóstico ONA e de profissionais
}

\author{
Personnel management at a pediatric unit from the perspective of the ONA diagnosis and professionals
}

Gestión de personal en unidad pediátrica en la perspectiva del diagnóstico ONA y de profesionales

Tereza Cristina Peixoto ${ }^{1}$, Maria José Menezes Brito², Letícia Corrêa Santana³

\section{RESUMO}

As exigências de qualidade nos hospitais têm impulsionado o aprimoramento da gestão de pessoas. O objetivo deste estudo foi compreender as práticas de gestão de pessoas na perspectiva do diagnóstico da Organização Nacional de Acreditação Hospitalar (ONA) e de profissionais de saúde de uma unidade de internação pediátrica. Trata-se de pesquisa qualitativa, descritiva, com coleta de dados primários e secundários. Os dados primários foram obtidos por meio de entrevistas semiestruturadas realizadas com um grupo heterogêneo de profissionais. Os dados secundários foram coletados mediante o diagnóstico ONA. O tratamento dos dados pela técnica de análise de conteúdo evidenciou fragilidades nas práticas de gestão de pessoas, apontadas no diagnóstico e exemplificadas nos relatos dos profissionais. Conclui-se que o diagnóstico é importante para o planejamento da gestão de pessoas, devendo ser utilizado juntamente com mecanismos para escuta dos profissionais.

Descritores: Administração de Recursos Humanos; Gestão da Qualidade; Serviços de Enfermagem.

\section{ABSTRACT}

Quality demands in hospitals have propelled the improvement of personnel management. The purpose of this study was to understand the practices of personnel management from the perspective of the diagnosis of the National Organization of Hospital Accreditation (ONA) and that of health professionals at a pediatric hospital unit. It consists of a qualitative descriptive study, with primary and secondary data collection. Primary data were obtained through semi-structured interviews performed with a heterogeneous group of professionals. Secondary data were collected through the ONA diagnosis. Data treatment using the technique of content analysis revealed frailties in personnel management practices, which were indicated in the diagnosis and exemplified in the statements of the professionals. The authors conclude that diagnosis is important for planning personnel management, and it should be used together with mechanisms that involve listening to the professionals.

Descriptors: Personnel Management; Quality Management; Nursing Services.

\section{RESUMEN}

Las exigencias de calidad en los hospitales ha impulsado el mejoramiento de la gestión de personal. Este estudio objetivó comprender las prácticas de gestión de personal en la perspectiva del diagnóstico de la Organización Nacional de Acreditación Hospitalaria (ONA) y de profesionales de salud de una unidad de internación pediátrica. Investigación cualitativa, descriptiva, con recolección de datos primarios y secundarios. Los datos primarios fueron obtenidos mediante entrevistas con guión semiestructurado con un grupo heterogéneo de profesionales. Los datos secundarios fueron recogidos mediante el diagnóstico ONA. El tratamiento de los datos según técnica de análisis de contenido evidenció fragilidades en las prácticas de gestión de personal, expresadas en el diagnóstico y ejemplificadas en los testimonios de los profesionales. Se concluye en que el diagnóstico es importante para la planificación de la gestión de personal, debiendo ser utilizado conjuntamente con mecanismos para escuchar a los profesionales.

Descriptores: Administración de Personal; Gestión de Calidad; Servicios de Enfermería.

\footnotetext{
${ }^{1}$ Psicóloga, Mestre em Enfermagem. Docente do Centro Universitário UNA e da Escola de Saúde Pública do Estado de Minas Gerais. Belo Horizonte, MG, Brasil. E-mail: terezacp7@gmail.com.

2 Enfermeira, Doutora em Administração. Professora Adjunta da Universidade Federal de Minas Gerais (UFMG). Belo Horizonte, MG, Brasil. E-mail: mjbrito@globo.com.

${ }^{3}$ Enfermeira. Enfermeira do Hospital Vera Cruz. Belo Horizonte, MG, Brasil. E-mail: enf santana@hotmail.com.
} 


\section{INTRODUÇÃO}

No mundo moderno, a gestão pela qualidade vem ganhando cada vez mais importância no campo empresarial, tanto pelo estágio de desenvolvimento das organizações, quanto pela globalização da economia. As organizações têm procurado o aprimoramento gerencial com medidas que possibilitem melhoria contínua na tomada de decisões, com ênfase na prevenção de eventos indesejáveis, a fim de minimizar perdas e maximizar oportunidades, se fortalecendo competitivamente no mercado(1).

Nas organizações hospitalares, a gestão pela qualidade tem adquirido, nos últimos anos, grande importância tanto no setor público, quanto no privado. A crescente adesão dos hospitais às políticas da qualidade tem proporcionado o aprimoramento da assistência prestada à população em geral, com mais qualidade e segurança para os pacientes e trabalhadores ${ }^{(2)}$.

Um dos pilares para a implantação da gestão com foco em qualidade é a gestão de pessoas. A gestão da qualidade entendida como norma auditável aborda a gestão de pessoas como um diferencial entre as organizações, considerando que os trabalhadores representam capital intelectual e criativo, assegurando a eficácia e competitividade organizacional. Nesse sentido, acredita-se que a captação dos melhores profissionais, a capacitação constante e o desenvolvimento individual de competências são primordiais para a implantação e manutenção do sistema de gestão(2).

Atualmente, o reconhecimento e certificação da qualidade da atenção e gestão dos hospitais estão diretamente relacionados à sobrevivência no mercado, tanto no setor público, quanto privado. A Organização Nacional de Acreditação Hospitalar - ONA(3) é uma certificação nacional que tem como objetivo promover a implantação de um processo permanente de avaliação e de certificação da qualidade dos serviços de saúde, permitindo o aprimoramento contínuo da atenção, de forma a melhorar a qualidade da assistência, em todas as organizações prestadoras de serviços de saúde. O processo para certificação é voluntário e realizado por instituições acreditadoras credenciadas pela ONA por meio de visita técnica. Tais visitas são denominadas visitas diagnósticas e propiciam, por parte dos avaliadores, o desenvolvimento de relatórios individuais por setores ${ }^{(3)}$.
A ONA visa um processo permanente de melhoria da qualidade assistencial, mediante a avaliação periódica do serviço. Para tal, foi elaborado o Manual Brasileiro de Acreditação Hospitalar (MBAH) destinado à avaliação contínua dos hospitais. O referido manual está organizado em seções e subseções com padrões de exigência para três níveis de complexidade da classificação para a qualidade assistencial. 0 nível 1 está relacionado à segurança em relação à estrutura física e seus requisitos são baseados nas leis da Vigilância Sanitária e Ministério da Saúde; o nível 2 está relacionado à organização e controle dos processos como rotinas e registros e o nível 3 refere-se às práticas de excelência, visando a melhoria continua dos processos mediante análise crítica dos indicadores ${ }^{(3)}$.

Nesse entendimento, o modelo de gestão pela qualidade deve enfatizar a gestão de pessoas compreendendo-a de forma sistêmica como um conjunto de políticas e práticas para orientar as relações interpessoais no cotidiano de trabalho na saúde ${ }^{(4)}$. No entanto, com relação à implementação da Gestão pela qualidade nos hospitais, não têm sido considerada a dimensão subjetiva dos trabalhadores para envolvimento, integração dos profissionais e conciliação de interesses entre trabalhadores e gestores ${ }^{(5)}$.

Na perspectiva de compreender as ineficácias da implementação da gestão de pessoas, ressalta-se a tensão entre capital e o trabalho influenciando a forma como os modelos de gestão são realizados no cotidiano organizacional, uma vez que não enfocam efetivamente o desenvolvimento e valorização dos trabalhadores, mas somente a instrumentalização e a normatização dos processos de trabalho. Dessa forma, contribuem para o incremento de mecanismos de manipulação dos trabalhadores ${ }^{(6)}$.

Dessa forma, para que a Acreditação Hospitalar seja uma importante ferramenta de gestão é necessário uma mudança cultural nas organizações de saúde, envolvendo qualificação da liderança do grupo gestor e dos profissionais, além de mecanismos para participação dos profissionais na gestão do trabalho(7).

Em face do exposto, o presente estudo teve como objetivo compreender as práticas de gestão de pessoas na perspectiva do diagnóstico da Organização Nacional de Acreditação Hospitalar e de profissionais de saúde de uma unidade de internação pediátrica. Parte-se do pressuposto de que os instrumentos do diagnóstico ONA 
e mecanismos de escuta da visão dos trabalhadores são relevantes para os planejamentos de gestão de pessoas, podendo contribuir para a elaboração de ações estratégicas voltadas para o desenvolvimento profissional dos trabalhadores e da organização.

\section{METODOLOGIA}

Estudo descritivo de abordagem qualitativa ${ }^{(8)}$, uma vez que se interessa pelos aspectos subjetivos e dinâmicos das práticas de gestão de pessoas. O cenário da investigação foi uma unidade de internação pediátrica de um hospital localizado na região metropolitana de Belo Horizonte-MG, com modelo de gestão colegiada já implantada, e em processo de inovações para a certificação (acreditação) ONA. A unidade de internação pediátrica utilizada como lócus de pesquisa encontravase, na ocasião da pesquisa, em processo de implantação da acreditação hospitalar.

Participou da pesquisa um grupo de gestores da unidade formado por gerente (um); coordenadores (um administrativo; um de enfermagem e um médico) e com um grupo heterogêneo de profissionais: dois psicólogos; dois médicos; dois enfermeiros; cinco técnicos de enfermagem; um assistente social; um fonoaudiólogo; um terapeuta ocupacional, um nutricionista e um profissional administrativo da rouparia, totalizando 21 profissionais entrevistados. Para a definição dos sujeitos da pesquisa foi considerada a representação de todas as categorias de profissionais que atuavam nos processos assistenciais e da gestão da unidade nos períodos diurno, noturno e nos finais de semana. Também foi incluído um profissional da rouparia envolvido no trabalho assistencial da unidade. A definição do número de participantes foi realizada com base no critério de saturação, não havendo, a priori, delimitação do número de entrevistados. Tal escolha se justificou por ser um dos critérios adotados e recomendados para pesquisas qualitativas $^{(9)}$.

Os dados foram coletados de duas fontes, sendo os dados primários, por meio de entrevistas com roteiro semiestruturado, e os dados secundários por meio de análise do diagnóstico ONA do hospital em estudo, realizado pelo Instituto Qualiza de Gestão no ano de 2009. Para análise documental do referido diagnóstico foi previamente elaborado um roteiro organizado de acordo com os eixos dos processos da gestão de pessoas por competências ${ }^{(10)}$, quais sejam, os processos de movimentação, de desenvolvimento e de valorização do trabalhador, assim como outros compromissos para a gestão de pessoas como a comunicação, informação e saúde e qualidade de vida.

Após a coleta dos dados secundários, foram realizadas as entrevistas no período de junho a setembro de 2010, com o referido grupo de participantes. As entrevistas foram realizadas individualmente, na unidade de internação. Os participantes foram previamente orientados quanto aos objetivos do estudo, tendo sido assegurado o anonimato e sigilo das informações. O Termo de Consentimento Livre e Esclarecido foi assinado pela totalidade dos sujeitos, conforme as recomendações da Resolução 196/96.

As entrevistas com roteiro semiestruturado iniciaram-se com questões norteadoras, conduzidas de forma flexível, para livre expressão dos entrevistados e aprofundamento por parte do entrevistador. Essas questões enfocaram aspectos referentes às dificuldades e facilidades encontradas no cotidiano do trabalho; à existência e funcionamento das reuniões de trabalho tanto intraprofissional quanto interprofissional; à participação nas decisões com relação ao trabalho; ao conhecimento e visão das estratégias para valorização do trabalhador, recrutamento, seleção, treinamento introdutório, capacitação, plano de carreira, avaliação de desempenho e qualidade de vida e saúde no trabalho.

Para a análise dos dados foi utilizada a análise de conteúdo(11). Para tanto, foi realizada a pré-análise dos dados das entrevistas; a exploração do material e o tratamento dos resultados(11). Foram extraídas as seguintes categorias temáticas, organizadas de acordo com a classificação dos processos de gestão de pessoas $^{(10)}$ : Práticas relacionadas ao processo de movimentação; Práticas relacionadas ao processo de desenvolvimento; Práticas relacionadas à valorização dos profissionais e Práticas relacionadas com a saúde e qualidade de vida no trabalho. Os dados primários e secundários foram analisados concomitantemente, configurando as categorias temáticas mencionadas, permitindo confrontação dos dados.

Os depoimentos das entrevistas foram identificados conforme as iniciais da categoria profissional correspondente a cada sujeito, para preservar o anonimato, por exemplo, Assistente Social - AS, alguns depoimentos foram identificados pelo vínculo profissional também, como RPA para trabalhadores que 
assinam Recibo para Pagamento Autônomo; os profissionais responsáveis pela gestão da unidade, como os coordenadores e o gerente foram identificados pela inicial G. Além disso, os resultados da análise de dados do diagnóstico ONA foram identificados com as iniciais de Análise Documental - AD.

Os resultados foram analisados à luz dos referenciais teóricos sobre gestão de pessoas por competências ${ }^{(10)}$ e no campo da gestão e do planejamento em saúde. Acredita-se que esse estudo possa contribuir para o aprimoramento em gestão de pessoas e com a política da qualidade nos hospitais.

O projeto que deu origem a investigação foi aprovado pelo Comitê de Ética em Pesquisa da UFMG (Protocolo ETIC 0054.0.203.000-10), bem como pelo Comitê de Ética do hospital utilizado como cenário de investigação.

\section{RESULTADOS E DISCUSSÃO}

Os resultados serão apresentados e discutidos de acordo com as categorias temáticas definidas, articulando os dados de fonte primária e secundária. A esse respeito cabe esclarecer que primeiramente serão apresentados os dados secundários referentes ao diagnóstico sobre as sugestões para melhorias na gestão e sobre as não conformidades do hospital. Em seguida serão apresentados os resultados advindos dos dados primários alcançados por meio das entrevistas realizadas com os sujeitos.

A primeira categoria relaciona-se às práticas de gestão de pessoas referentes ao processo de movimentação, o qual compreende a captação (recrutamento e seleção), a internalização (treinamento introdutório), as transferências, promoções, expatriação e recolocação, independente do vínculo empregatício do trabalhador ${ }^{(10)}$.

Na análise do diagnóstico ONA, foram identificadas as seguintes ações voltadas para melhorias no processo de movimentação: análise dos motivos de desligamento dos funcionários e do índice de rotatividade do quadro funcional, a fim de implantar programa de alinhamento das competências dos funcionários admitidos pelo concurso e, ainda, análise das descrições de cargos $e$ funções para melhoria das práticas de seleção, recrutamento e desenvolvimento (AD).

O diagnóstico ONA reforça ainda: a necessidade de uma política de pessoas baseada em valores institucionais que contemple todas as categorias profissionais, independente do vínculo empregatício, bem como a atualização das descrições de cargos e funções para a garantia de melhores resultados nos processos de recrutamento, seleção e desenvolvimento dos recursos humanos $(A D)$.

No hospital em estudo, a prática de captação é nomeada pelo Setor de Recursos Humanos como seleção. Essa prática encontra-se prescrita no Regime Jurídico Único(12) e deve ocorrer mediante a realização de concurso público. Contudo, devido à escassez de concursos públicos no decorrer dos anos, outras formas de contratação foram adotadas para o suprimento de servidores aposentados, falecidos ou com licença médica. A título de exemplo, pode-se mencionar a contratação por meio da Fundação de Apoio Universitário e os profissionais que assinam Recibo de Pagamento Autônomo (RPA), sem que haja vínculo empregatício. A despeito da contratação na modalidade RPA ser caracterizada por contratos de prestação de serviços em caráter temporário, observa-se, na prática, que muitos profissionais permanecem na instituição por períodos muito prolongados, convivendo cotidianamente com os servidores efetivos do hospital. Além dos vínculos já mencionados, a unidade conta com profissionais terceirizados para o desempenho de atividades relacionadas aos serviços gerais, vigilância, alguns cargos administrativos e os menores vinculados à Cruz Vermelha.

$\mathrm{Na}$ visão dos profissionais a seleção para os contratados e RPAs não ocorre de forma homogênea. Alguns são submetidos à prova teórica e prática e outros realizam somente entrevista. Segundo o depoimento de uma das entrevistadas o processo não é adequado para suprir as demandas do serviço:

Eu acho interessante a seleção, mas, por exemplo, só tem a parte teórica, não tem a parte prática. Quando eu entrei nem era assim, era só uma análise de currículo, agora é que eles fazem uma prova e ai fazem tipo um ranking e vai chamando de acordo com a necessidade do hospital. Mas muitas vezes o profissional chega aqui, mas não serve pra trabalhar aqui, então aí, talvez a prova prática seria uma forma de filtrar também (E.1).

O depoimento de E.1 permite que sejam evidenciadas desigualdades nas práticas de seleção, o 
que afeta as categorias profissionais de maneira generalizada. Além disso, tal prática não se encontra fundamentada nas competências profissionais, conforme apontado pelo diagnóstico ONA.

Também foram feitas críticas concernentes ao processo seletivo para o servidor público, como exemplificado:

Funcionário entra aqui muito por concurso público, então o hospital não consegue selecionar pessoas com perfil. É...porque a pessoa que vem do concurso público você só entrevista e entra, ela passou no concurso e tem que ser admitida (AS).

Essa dificuldade expressa por AS também foi identificada no diagnóstico ONA, no qual foi apontada:

Necessidade de planejamentos para análise dos motivos de desligamento dos funcionários e do índice de rotatividade do quadro funcional, com a finalidade de subsidiar a implantação de um programa de alinhamento das competências dos funcionários admitidos via concurso, bem como a análise das descrições de cargos e funções para melhorias nas práticas de seleção, recrutamento $e$ desenvolvimento $(A D)$.

A esse respeito, ressalta-se que os hospitais universitários possuem a dupla missão de proporcionar assistência de alta complexidade e de configurar-se como espaço de excelência no ensino e pesquisa. Desta forma, agregam alta concentração de recursos de saúde (físicos, humanos e financeiros) e exercem papel político nas regiões em que estão inseridos ${ }^{(13)}$. Apesar das novas exigências de qualidade para certificação desses hospitais pelo Ministério da Educação e Cultura e pelo Ministério da Saúde, esses hospitais ainda enfrentam sérios problemas na gestão de pessoas, em face da desregulamentação de Recursos Humanos no SUS ${ }^{(13)}$.

Nesse contexto, salienta-se a necessidade de definição, por parte da organização, dos seguintes aspectos: perfil, inclusive comportamental esperado do profissional, entregas desejadas das pessoas para atender às necessidades da organização tanto presentes quanto futuras, condições de trabalho, condições de desenvolvimento profissional, como também clareza das condições contratuais a serem oferecidas ${ }^{(14)}$.
Рага tal, atualmente o planejamento da gestão de pessoas tem enfatizado a gestão de pessoas por competência para eficácia e competitividade das organizações. Esse modelo instalou-se inicialmente como um processo sistematizado, com êxito nos processos seletivos, a partir da avaliação do perfil das pessoas para as competências dos cargos. Contudo, nas instituições de saúde a gestão de competências é ainda mais complexa, pois a definição de competências deve estar alinhada tanto para a sustentabilidade e competitividade da organização, como para o desenvolvimento dos profissionais e também para atenção às necessidades dos clientes e seus familiares ${ }^{(15)}$.

Entende-se por competências os conhecimentos teóricos e práticos (experiências, representando o saber), assim como as habilidades profissionais (técnicas, representando o saber-fazer) e as atitudes do profissional (representando o saber-ser) em um determinado contexto de trabalho(10). Na gestão de pessoas por competências, são definidas inicialmente, as competências essenciais à organização, que devem estar alinhadas ao planejamento estratégico. Logo em seguida essas competências devem ser articuladas com as competências dos trabalhadores, necessárias para o exercício do trabalho. Após esse processo, realiza-se um levantamento das competências individuais dos profissionais existentes na organização, a fim de possibilitar a análise da lacuna existente entre as competências necessárias para a competitividade organizacional (competências organizacionais), para qualidade do trabalho em saúde (competências profissionais) e as competências individuais, dos trabalhadores. Essa análise subsidia o planejamento para todas as práticas da gestão de pessoas(10).

Outra prática de gestão de pessoas pertencente a essa categoria temática é o treinamento introdutório. A esse respeito os gestores da unidade de internação apontaram lacunas, como por exemplo, o fato desse treinamento ser planejado no âmbito do Programa de Capacitação do Hospital, mas não atingir com regularidade os profissionais que ingressam no serviço:

Acho (...) um pouco falha a capacitação geral do hospital. Porque o hospital está sempre dando treinamento, o hospital está sempre com um grupo novo de funcionário. Então você vê, não sei se é porque eu tenho muito tempo 
que eu estou aqui, a diferença das pessoas que chegam $e$... ocorrem falhas no trabalho, alguma coisa acontece, não porque ele quer, mas porque chega e às vezes não foi treinado adequadamente (G. 2).

Essa situação fragiliza a internalização do trabalhador à organização, tendo em vista que o treinamento introdutório favorece a integração do profissional e o estabelecimento do seu contrato psicológico com a organização(10). Assim, esse treinamento deve estar alinhado aos valores institucionais, sendo uma importante prática na gestão de pessoas, como descrito no diagnóstico ONA.

Além disso, o treinamento introdutório deve se inserir em um programa de capacitação mais amplo, que contemple capacitações corporativas para a difusão dos valores organizacionais, além de capacitações para a formação de competências essenciais e profissionais dos trabalhadores ${ }^{(10)}$.

No âmbito do trabalho em saúde, a gestão de pessoas por competências deve enfatizar, também, a competência social e as atitudes proativas no enfrentamento de problemas cotidianos dos profissionais de saúde, além de priorizar a satisfação dos usuários $^{(15)}$. Salienta-se, pois, a importância do desenvolvimento de competências dos profissionais da enfermagem, haja vista a complexidade dos processos de trabalho nos quais se encontram envolvidos, abrangendo ações de cunho assistencial, gerencial e de ensino. Desta forma, os profissionais desta categoria, em especial, devem estar instrumentalizados para atuarem nas diferentes etapas do processo de gestão de pessoas por se tratar de um dos quesitos mais significativos da qualidade dos serviços e, ainda, por envolver um grande número de profissionais, impactando inclusive nos custos hospitalares ${ }^{(16)}$. Para tal, é imprescindível a formação de enfermeiros líderes para o estímulo do trabalho em equipe e para o envolvimento dos profissionais com a gestão(17).

A segunda categoria temática corresponde às práticas de gestão do processo de desenvolvimento dos profissionais, relacionados às práticas de capacitação, carreira e desempenho. A esse respeito, as análises do diagnóstico ONA permitiram a identificação de: necessidade de melhorias voltadas para a definição de ações formais de capacitação, promoção e carreira de acordo com os resultados obtidos na avaliação de desempenho dos profissionais e necessidade de homogeneidade na definição e organização das capacitações dentre as categorias profissionais (AD).

Dentre os problemas apontados pelos profissionais destacam-se: o desconhecimento dos temas a serem trabalhados nas capacitações, bem como na divulgação das mesmas, como no seguinte relato:

Às vezes acontecem coisas que aparecem que não chegam até a gente, assim não sei se é porque já colocam alguém na frente, sabe? Com relação a cursos mesmo. Tem muitos cursos, só que a gente não chega a ter conhecimento (ADM.)

É possível observar, além disso, heterogeneidade na forma como essas práticas são realizadas e falta de integração entre as práticas de gestão de pessoas. A esse respeito destaca-se o relato do entrevistado sobre a relação entre as capacitações e as necessidades do trabalho, que poderia ser identificada por meio da avaliação de desempenho, como nesse relato:

Existe a capacitação, mas só que ela não atende a todo mundo, eu acho que é deficitária, e às vezes atende, alguns casos atende, existe uma capacitação, mas que não é a capacitação que as pessoas desejam. Então existe uma oferta às vezes que não é a demanda (AS).

A esse respeito cabe salientar que os programas de capacitação, no hospital em foco, devem enfocar o desenvolvimento de lideranças para os gerentes e coordenadores, imprescindível nos processos no trabalho, uma vez que atualmente, a tomada de decisão tem sido delegada às equipes de trabalho, por se encontrarem mais próximas dos clientes ${ }^{(16)}$.

As ações de capacitação podem ser divididas em ações formais e informais. As ações formais referem-se a cursos, com conteúdos programáticos específicos, envolvendo metodologias didáticas específicas, material bibliográfico; as informais referem-se a atuações no trabalho, como coordenação ou participação em projetos, visitas interinstitucionais, acompanhamentos de estágios. Рara o desenvolvimento das habilidades do trabalhador em cargos com atribuições mais complexas, como a de gestores é necessária maior participação nessas ações informais ${ }^{(10)}$. 
Рага a formação dos gestores como líderes das equipes de trabalho, salienta-se o desenvolvimento de competência interpessoal, incluindo habilidades interativas capazes de promover trabalhos coletivos e de humanização na atenção à saúde, além de habilidades técnicas para a gestão do trabalho. Ressalta-se ainda, que as habilidades interativas favorecem a criatividade, intuição, autoconhecimento e interação dos profissionais entre si e com os pacientes ${ }^{(17)}$.

Além disso, para a formação e qualificação dos profissionais da saúde, um instrumento importante é a pesquisa de satisfação dos clientes. Essa pesquisa deve ser utilizada para a identificação de aspectos necessários para o aprimoramento dos profissionais, cabendo aos líderes das equipes o estímulo dos profissionais para a valorização desse instrumento como componente importante para a cultura de aprendizado contínuo na organização com foco nos clientes ${ }^{(18)}$.

Outra prática que integra o processo de desenvolvimento é o plano de carreira. Na unidade em estudo, essa prática é prescrita somente para o servidor público federal e é regulamentada pelo Regime Jurídico Único(12):

Eu nunca tive aumento, sou de RPA! (...) Eu também tive essa informação de uma colega minha que é RPA há quatro anos e que o salário é o mesmo de hoje, a gente recebe por horas trabalhadas. Então é uma queixa que a gente tem, porque o nosso poder aquisitivo vai só caindo, né? E isso, não é nada estimulante. (P1-RPA)

A diversidade de vínculos e, consequentemente, a desigualdade com relação ao Plano de Carreira entre os profissionais de saúde pode favorecer a desmotivação no trabalho e desentendimentos entre os profissionais.

Ressalta-se que o Plano de Carreira, no hospital em foco, está regulamentado pelo Regime Jurídico Único, por ser um hospital público ${ }^{(12)}$. No entanto, a inexistência de concurso público por muitos anos favoreceu a existência de outros vínculos profissionais, como os contratados pela Fundação Universitária e os profissionais que assinam Recibo de Pagamento Autônomo (RPA), além de trabalhadores de empresas terceirizadas, como os de serviços gerais e vigias. Essa situação é encontrada em muitos hospitais universitários no Brasil, e corresponde à situação de desregulamentação de Recursos Humanos no SUS, desde a constituição de $1988^{(13)}$.

Nesse sentido, evidencia-se em muitos hospitais públicos, a existência de diversos vínculos profissionais com jornadas de trabalho e salários distintos, exercendo as mesmas funções. Assim como trabalhadores com contratos precários, que ingressaram sem concurso público e sem direitos trabalhistas. Essas situações são graves e têm provocado insatisfação e desvinculação dos trabalhadores com os serviços públicos ${ }^{(13)}$.

$\mathrm{Na}$ unidade em estudo, somente os servidores públicos tinham direito ao Plano de Carreira. No entanto, segundo os entrevistados para a progressão salarial é necessário a participação em cursos para qualificações e avaliação de desempenho. Contudo, em decorrência das falhas na divulgação dos cursos no hospital ou, até mesmo por dificuldades na liberação dos profissionais para participarem dos cursos, a progressão salarial no Plano de Carreira não tem sido acessível a todos.

Quanto à avaliação de desempenho, alguns entrevistados afirmaram que essa prática tem sido formal e burocrática, uma vez que, poucos coordenadores oferecem feedback aos profissionais a respeito das melhorias necessárias no trabalho, numa relação dialógica, como exemplificado no seguinte relato:

Eu acho que a avaliação de desempenho nos moldes que está hoje, não avalia nada. É do tipo assim marcar com um $X$ e eu acho que marcar a opção não avalia nada. Ela é uma estatística do que você acha que está fazendo bem e do que você acha que não está fazendo bem e do que seu chefe acha que você está fazendo e do que não acha. São questões fechadas em que você não pode opinar (AS).

Além do aspecto mencionado por AS, a avaliação de desempenho é caracterizada como uma prática desarticulada das demais, o que a torna ainda mais burocrática por não favorecer o crescimento do profissional e da organização, como exemplificado pelo relato:

Ah! Particularmente eu acho que essa avaliação é mais para garantir o aumento de salário. Eu acho que ela não traz crescimento para o funcionário. Porque se tem um item que o funcionário tem que melhorar, então ele deveria ser trabalhado pra essa melhora, mas não. Avalia, 
ele não está muito bom, mas ele não é trabalhado para essa melhora (ADM).

Essa avaliação consiste na análise sistemática do desempenho dos profissionais no cumprimento das metas estabelecidas e do potencial de desenvolvimento do trabalhador ${ }^{(10)}$. A avaliação de desempenho se destina, também, à identificação de problemas de gerência, bem como à mensuração e integração das pessoas à organização, adequação das pessoas aos cargos e identificação das necessidades de capacitações dos profissionais.

Quando há desvinculação da prática da avaliação de desempenho com a de capacitação, essa se torna restrita a aspectos burocráticos, servindo somente para aumentos salariais previstos no Plano de Carreira(10). Esse aspecto estritamente burocrático da avaliação de desempenho na unidade em estudo foi evidenciado nas entrevistas. Outro aspecto que favorece a burocratização dessa prática são as lacunas identificadas no retorno dados aos trabalhadores quanto a aspectos em que são identificadas necessidades de melhorias. Necessário se faz que os coordenadores sejam capacitados para a realização dessa tarefa, haja vista a relevância do processo dialógico com o profissional, inclusive para avaliação do processo de trabalho(19).

Na categoria temática que corresponde as práticas relacionadas à valorização dos profissionais, ou seja, as práticas de remuneração e benefícios observou-se por meio do diagnóstico ONA: ausência de ações propositivas, o que aponta a necessidade de criação de benefícios para os profissionais (AD). A esse respeito um dos entrevistados que assina Recibo de Pagamento Autônomo, relatou:

Eu tô aqui, desde 2008 nunca tive aumento, é...os médicos tiveram. Porque são mais fortalecidos, né...começou a faltar médico aqui no hospital por causa do salário, mas aí teve para eles e não teve para o resto. E eu tive uma informação de uma colega minha que é RPA há 4 anos que o salário é o mesmo que é o hoje, a gente recebe por horas trabalhadas. Então. é uma queixa que a gente tem, porque o nosso poder aquisitivo vai só caindo, né? E isso não é nada estimulante $(P 1)$.

Nesse contexto, percebe-se que o hospital não adota práticas de benefícios, serviços ou facilidades, necessários para incentivar e valorizar os trabalhadores ${ }^{(10)}$. Somente para os servidores públicos, o Regime Jurídico Único regulamenta as gratificações, adicionais e benefícios para os servidores públicos federais $^{(12)}$.

A última categoria temática corresponde às práticas de saúde e qualidade de vida no trabalho, que representam os compromissos mútuos entre a organização e as pessoas ${ }^{(10)}$, como o contrato psicológico, o clima organizacional, as dinâmicas interpessoais e intergrupais e os compromissos com a preservação biopsicossocial (saúde, segurança no trabalho e ergonomia) e com a qualidade de vida, ambiente e participação nos processos decisórios.

A esse respeito o diagnóstico ONA apresentou sugestões voltadas para: a promoção de melhorias no programa para a Saúde e Qualidade de Vida no Trabalho (QVT) (AD). Com também explicitou: a inexistência de um programa de segurança ocupacional (AD). Nesse sentido, - diagnóstico enfatizou: a necessidade de desenvolvimento de ações políticas junto aos órgãos competentes com vistas a promover ações estruturais $e$ operacionais que viabilizem a assistência à saúde física $e$ mental dos trabalhadores (AD).

No que diz respeito à inexistência de um programa de Saúde e Segurança no trabalho o relato a seguir corrobora com os achados do diagnóstico.

Se você adoece o que acontece? Pra quem é RPA você fica sem nada. (...) Já houve situações de outras pessoas darem o plantão para uma pessoa doente para que ela continuasse recebendo, mas, mas isso, eu já ouvi falar uma ou duas vezes (M2-RPA).

Outro relato deixa clara a necessidade de um programa de Saúde e Segurança no trabalho:

É os exames periódicos... a vacinação a gente sempre tem direito, isso a gente tem sim. Mas, não é feito um controle de como que anda a vacina dos profissionais. Quando tem uma campanha de vacinação aí eles conferem o cartão, aí tem que levar o cartão pra ver como estão as vacinas, mas não acompanham (F.-Fundação).

As Práticas de Saúde e Qualidade de Vida no Trabalho são necessárias para que o hospital aprimore seu programa existente, a fim de assegurar o 
cumprimento das normas de controle de imunização dos profissionais e de segurança no trabalho, como também para a criação de mecanismos para o cuidado com a saúde mental dos profissionais de saúde. Para tanto, é importante que sejam criados espaços que possibilitem a reflexão crítica sobre fatores que contribuam para a saúde e adoecimento no trabalho, incluindo discussão sobre o lidar com o sofrimento e a morte de pessoas.

Ademais, para a promoção da saúde dos profissionais é importante reconhecer que saúde, doença e trabalho referem-se a questões amplas, envolvendo saberes transdisciplinares, considerando a dimensão subjetiva e a articulação com políticas públicas saudáveis. As ações destinadas à saúde e qualidade de vida no trabalho devem enfocar o compromisso político e crítico em defesa da saúde e do direito ao trabalho digno(20). Nesse contexto, outro aspecto importante para a qualidade de vida e saúde no trabalho é a integração dos trabalhadores em equipes multiprofissionais e a participação dos profissionais na gestão.

Nessa direção, o diagnóstico ONA constatou: fragilidades da integração multiprofissional para o planejamento da assistência e do estabelecimento de uma política de comunicação institucional para a melhoria dos processos de comunicação e informação (AD). A comunicação e informação organizacional compõem os processos de apoio na gestão e são de responsabilidade de toda a organização(10).

O trabalho em equipe multiprofissional também apresenta falhas, as quais foram apontadas pelos entrevistados ao relatarem que existem reuniões em equipe somente para os projetos especiais da unidade como, atendimento aos adolescentes; atenção domiciliar e cuidados paliativos. Não temos reuniões para discutir os casos, os encontros são aqui na pediatria. São reuniões informais para discussão de casos quando a gente precisa (F1).

Com relação à participação dos profissionais nos processos decisórios do trabalho, o hospital implantou, há mais de 10 anos, o modelo de gestão colegiada. No entanto, ainda não há efetiva participação dos trabalhadores na gestão dos serviços e autonomia das unidades, assim como há falhas na integração entre os profissionais de saúde, como apresentado nos relatos:

Olha se participam das decisões, isso deve ocorrer mais durante o dia, né? Então essa informação é um pouco complexa para eu te dar. Até porque a gente não tem reuniões. As reuniões administrativas não têm de jeito nenhum à noite. (T. 4).

O relato seguinte do gestor exemplifica a pouca autonomia das unidades de produção:

A coisa é repassada... Não é nem repassado pra te falar a verdade, porque as vezes já chega pra gente de um jeito e você só comunica pra frente, não existe um: Olha, nós estamos planejando fazer isso e isso assim, a ideia da gestão é esta... Não tem muito isso, não, pelo menos eu sinto isto (G.2).

Nesse sentido, deve-se estimular postura ativa e participativa dos profissionais na elaboração de novas estratégias para a saúde no trabalho com foco na promoção da saúde(20). Ressalta-se que o modelo de gestão colegiada implantado no hospital favorece a gestão participativa, descentralizando a gestão por meio da horizontalização do organograma. Рara tal, são criadas unidades de produção com autonomia para a avaliação e planejamento da assistência em colegiados na unidade, com representação de todos os profissionais. Além disso, os representantes desses colegiados articulam-se com a alta direção em colegiado gestor $^{(21)}$.

Ademais, esse modelo de gestão favorece também a integração entre as categorias profissionais. No entanto, para o funcionamento eficaz desse modelo é necessário mudança da cultura, principalmente no que se refere às corporações profissionais que mantém a fragmentação e as disputas de poder entre os profissionais de saúde(21).

\section{CONSIDERAÇÕES FINAIS}

O presente estudo apresentou a visão de profissionais de uma unidade de internação pediátrica sobre as práticas de gestão de pessoas de acordo com as orientações do diagnóstico ONA. Evidenciou-se que as orientações presentes no diagnóstico apontam melhorias também identificadas pelos profissionais de saúde. Além disso, ressalta-se a importância das práticas de gestão de pessoas estarem integradas entre si para favorecer o desenvolvimento organizacional e dos trabalhadores, abrangendo ações para a Saúde e Segurança no trabalho. 
Dessa forma, para que a gestão pela qualidade seja implementada eficazmente, é necessário considerar os interesses e a dimensão subjetiva dos profissionais, elaborando estratégias que promovam o desenvolvimento, valorização e qualidade de vida no trabalho dos profissionais e da organização.

O instrumento de diagnóstico da ONA pode contribuir para levantamento de pontos importantes para a elaboração estratégica da gestão de pessoas, não prescindindo da valorização de outros mecanismos para a participação dos profissionais nesse processo, como, por exemplo, reuniões e pesquisas.

\section{REFERÊNCIAS}

1. Araujo LG.. Gestão de pessoas: Estratégias e Interação Organizacional. São Paulo: Atlas; 2006.

2. Fadel MAV., Filho Regis VI. Percepção da qualidade em serviços públicos de saúde: um estudo de caso. Rev. Adm Pública. 2009;43(1):07-22.

3. Manzo BF, Brito MJM, Corrêa AR. Implicações do processo de Acreditação Hospitalar no cotidiano de profissionais de saúde. Rev. esc. enferm. USP [Internet]. 2012 [cited 2012 Mai 25]; 46(2):38894. Available from: http://dx.doi.org/10.1590/S008062342012000200017.

4. Bezerra, ALQ. Os desafios na gestão de pessoas. Rev. Eletr. Enf. [Internet]. 2004[cited $2012 \mathrm{dec} 31$ ];6(2):7-8. Available from: http://www.fen.ufg.br/fen_revista/revista6 2/editorial.html. 5. Sá MC, Azevedo SC. Subjetividade e gestão: explorando as articulações psicossociais no trabalho gerencial e no trabalho em saúde. Ciênc Saúde Colet. 2010;15(5):242-66.

6.Faria JH., organizador. Análise crítica das teorias e práticas organizacional. São Paulo: Atlas; 2007.

7 Duarte MSM, Silvino ZR. Acreditação hospitalar x qualidade dos serviços de saúde. R. pesq.: cuid. fundam. online [Internet]. 2010 [cited 2012 dec 31];2 Suppl:182-5. Available from:

http://www.seer.unirio.br/index.php/cuidadofundamental/article/vi ewFile/858/pdf 112

8. Minayo MCS, organizadora. Pesquisa social. Teoria, método e criatividade. $25^{\text {a }}$ ed. Petrópolis: Vozes; 2007.

9. Fontanella, B. J. B.; Ricas J.; Turato, E. R. Amostragem por saturação em pesquisas qualitativas em saúde: contribuições teóricas. Cad Saúde Publica, 2008 jan;24(1):17-27.

10. Dutra JS. Competência: conceitos e instrumentos para a gestão de pessoas na empresa moderna. São Paulo: Atlas; 2009.

11. Bardin L. Análise de conteúdo. São Paulo: Martins Fontes; 2009.

12. Ministério da Administração Federal e Reforma do Estado. Lei nº 8.112, de 11/12/90. Regime Jurídico Único Consolidado. Brasília (Brasil): MARE; 1998.

13. Médici AC. Hospitais Universitários: passado, presente e futuro. Rev. Assoc. Med. Bras. [Internet]. 2001 [cited 2012 dec 31];47(2):149-56. Available from: http://dx.doi.org/10.1590/S010442302001000200034.

14. Organização Pan-Americana de Saúde-OPAS. A transformação da gestão de hospitais na América Latina e Caribe. Brasília (Brasil):MARE; 1998.

15. Ruthes, R. M.; Cunha, I. C. K. O. Os desafios da administração hospitalar na atualidade. Rev Adm Saúde. 2007;9(36):93-102. 16. Aguiar ABA, Costa, RSB, Weirich, CF, Bezerra, ALQ. Gerência dos serviços de enfermagem: um estudo bibliográfico. Rev. Eletr. Enf. [Internet]. 2005 [cited 2012 dec 31];7(3):308-26. Available from: http://www.fen.ufg.br/fen_revista/revista7 3/original_09.htm. 17. Munari DB, Bezerra ALQ. Inclusão da competência interpessoal na formação do enfermeiro como gestor. Rev. bras. enferm
Cabe lembrar também que o sucesso na implantação de um Sistema de Gestão de pessoas está relacionado ao comprometimento e apoio da alta administração da organização, mas também dos profissionais e, dessa forma, devem estar articuladas à política e diretrizes gerenciais as estratégias para o desenvolvimento dos profissionais.

Esse estudo refere-se à unidade do estudo, novos estudos em outras organizações são importantes para comparação dos resultados e aprofundamento sobre diagnósticos para a gestão de pessoas em hospitais.

[Internet]. 2004 [cited 2012 May 10];57(4):484-6. Available from: http://www.scielo.br/pdf/reben/v57n4/v57n4a20.pdf.

18. Ruthes RM, Feldman LB, Cunha ICKO. Foco no cliente: ferramenta essencial na gestão por competência em enfermagem. Rev. bras. enferm. [Internet]. 2010 [cited 2012 May 10];63(2):317-21. Available from: http://www.scielo.br/pdf/reben/v63n2/23.pdf. 19. Lima AFC, Gonçalves VLM, Nori A, Nomura FH. Percepção da equipe de enfermagem de um hospital universitário acerca da avaliação de desempenho profissional. Rev Gaúcha Enferm. 2007;28(3):393-400. [Internet]. 2010 [cited 2012 May 28];28(3):393400. Available from: http://seer.ufrgs.br/RevistaGauchadeEnfermagem/article/view/469 1

20. Cavalcante CAA, Nóbrega JAB, Enders BC, Medeiros SM. Promoção da Saúde e trabalho: um ensaio analítico. Rev. eletr. enferm [Internet]. 2008 [cited 2012 May 28];10(1):241-248. Available from: http://www.fen.ufg.br/revista/v10/n1/v10n1a23.htm 21. Bernardes A, Cecilio LCO, Évora YDM, Gabriel CS, Carvalho MB. Modelo de gestão colegiada e descentralizada em hospital público: a ótica da equipe de enfermagem. Rev. Latino-Am. Enfermagem [Internet]. 2011;19(4):1003-10. Available from: http://www.scielo.br/pdf/rlae/v19n4/pt 20.pdf.

Artigo recebido em 20/05/2011. Aprovado para publicação em 08/05/2012. Artigo publicado em 31/12/2012. 